\title{
Evaluation of Different Modalities of anterior Cervical Discectomy for Treatment of Single and Double Level Cervical Disc Herniation
}

\author{
Hassan Mohammed*, Mohamed Abd El Baset Khalaf and Roshdy Abd El Aziz El Khayat \\ Neurosurgery Department, Assiut University Hospital, Assiut, Egypt
}

Submission: December 15,2017; Published: September 04, 2018

*Corresponding author: Hassan Mohammed, Neurosurgery Department, Assiut University Hospital, Assiut, Egypt; Email: h_moh_h@yahoo.com

\begin{abstract}
Cervical disc herniation and degenerative disease of the cervical spine are the most common causes of cervical cord and nerve root dysfunction. It is found that after the age of 40 almost $60 \%$ of the population will have radiographic evidence of degenerative changes, and after the age of $65,95 \%$ of men and $70 \%$ of women have radiographic evidence of degenerative changes [1]. Since the first description of the anterior cervical discectomy with fusion by Cloward and Smith in 1958 respectively in 1955, and the cervical anterior discectomy without fusion in 1960 by Hirsch a debate is started which of both methods is the best. While this discussion is still not closed, the advent of the cervical disc prosthesis has contributed to extra confusion. Instead of two possibilities, nowadays three possible treatments concur with each other: anterior cervical discectomy without implantation of any structure, anterior cervical discectomy with fusion, and finally, cervical discectomy with implantation of disc prosthesis [2]. Nowadays anterior cervical discectomy and fusion (ACDF) may be considered the standard procedure for treatment of degenerative disc disease of the cervical spine. However, there is evidence that ACDF may result in progressive degeneration of the adjacent segments [3].
\end{abstract}

Total intervertebral disc replacement (TDR) is designed to preserve motion, avoid limitations of fusion, and allow patients to quickly return to routine activities. The primary goals of the procedure in the cervical spine are to restore disc height and segmental motion after removing local pathology. A secondary intention is the preservation of normal motion at adjacent cervical levels, which may be theorized to prevent later adjacent level degeneration. It avoids the morbidity of bone graft harvest, it also avoids complications such as pseudarthrosis, and issues caused by anterior cervical plating and cervical immobilization side effects [4].

\section{Our study included}

Twenty patients with cervical disc herniation or spondylosis, with radiculopathy, which had not responded to conservative treatment (relative rest, soft collar, physiotherapy, and medication during at least 6 weeks), were treated by anterior decompression and cervical disc replacement. The technique followed anterior decompression differed according to the way of reconstruction at each level and the patients were accordingly classified into three groups:

I. Group A (1-level fusion): where the anterior decompression was accomplished by single level cervical discectomy, and then insertion of cervical cage at this level.

II. Group B (2-level fusion): where the anterior decompression was accomplished by double level cervical discectomy, and then insertion of cervical cage at both levels.

III. Group C (hybrid construct): where the anterior decompression was in the form of one level cervical discectomy, followed by cage implantation at this level and another level cervical discectomy followed by insertion of cervical disc prosthesis at the same time.

The ages in our patient population ranged from 30 to 50 years, with a mean of $40 \pm 5.9$ years (mean \pm standard deviation). Eleven out of the twenty patients $(55 \%)$ were males, and $9 / 20(45 \%)$ were females. 20 patients with cervical spondylosis at one or two levels were presented. The commonest level affected is C5-C6 level. The most common complaint of patients is neck pain and radiculopathy All these patients were evaluated preoperatively clinically and radiologically and followed up for a period of 1 month to 12 months and finally we conclude that: anterior cervical discectomy followed by single level cervical fusion was done on 13 patients, while 5 patients were subjected to anterior cervical discectomy followed by double level cervical fusion and another 2 patients had anterior cervical discectomy followed by cervical artificial disc replacement at one level and zero profile implant insertion and fusion at another level.

Abbreviations: ACDF: Anterior Cervical Discectomy And Fusion; TDR: Total Intervertebral Disc Replacement; ACDA: Artificial Cervical Disc Arthroplasty

Keywords: Degenerative disease; Possibilitie; Implantation; Pseudarthrosis; Immobilization; Patients; Artificial cervical disc; Arthroplasty; Radiographic evidence; Fusion; Surgery; Neutral; Flexion; Approach; Anatomic landmarks; Symptoms 


\section{Introduction}

The cervical spine consists of three atypical and four typical cervical vertebrae. Typical cervical vertebrae, C-3 to C-6, include a vertebral body, two pedicles, two lateral masses, two laminae, and a bifid spinous process. The seventh cervical vertebra is slightly different in it has a transitional form, it has a larger spinous process that is not bifid. Atypical vertebrae include the atlas (C1), the axis (C2), and the $7^{\text {th }}$ cervical vertebra [5]. Cervical disc herniation and degenerative disease of the cervical spine are the most common causes of cervical cord and nerve root dysfunction. It is found that after the age of 40 almost age of 65 , $95 \%$ of men and $70 \%$ of women have radiographic evidence of degenerative changes. Since the first description of the anterior cervical discectomy with fusion by Cloward and Smith in 1958 respectively in 1955, and the cervical anterior discectomy without fusion in 1960 by Hirsch a debate is started which of both methods is the best. While this discussion is still not closed, the advent of the cervical disc prosthesis has contributed to extra confusion. Instead of two possibilities, nowadays three possible treatments concur with each other: anterior cervical discectomy without implantation of any structure, anterior cervical discectomy with fusion, and finally, cervical discectomy with implantation of disc prosthesis.

Nowadays anterior cervical discectomy and fusion (ACDF) may be considered the standard procedure for treatment of degenerative disc disease of the cervical spine. However, there is evidence that ACDF may result in progressive degeneration of the adjacent segments. Twenty-five percent of patients undergoing cervical fusion will have new onset of symptoms within 10 years of that fusion. Other reports have helped to shed light on the recurrence of neurological symptoms and degenerative changes adjacent to fused cervical levels. Segments adjacent to a fusion may have an increased range of motion and increased intradiscal pressures. Total intervertebral Disc Replacement (TDR) is designed to preserve motion, avoid limitations of fusion, and allow patients to quickly return to routine activities. The primary goals of the procedure in the cervical spine are to restore disc height and segmental motion after removing local pathology. A secondary intention is the preservation of normal motion at adjacent cervical levels, which may be theorized to prevent later adjacent level degeneration. It avoids the morbidity of bone graft harvest, it also avoids complications such as pseudarthrosis, and issues caused by anterior cervical plating and cervical immobilization side effects.

\section{Patients and Methods}

\section{Study design}

This is a dual Centre clinical trial comparing the treatment of 20 patients with degenerative cervical disc disease by anterior cervical discectomy. Twenty cases were operated and evaluated over a period of 1 year at the department of Neurosurgery Assiut University Hospital and Gamal Abd El Naser Hospital, Alexandria.

\section{Patient population}

Twenty patients with cervical disc herniation or spondylosis, with radiculopathy, which had not responded to conservative treatment (relative rest, soft collar, physiotherapy, and medication during at least 6 weeks), were treated by anterior decompression and cervical disc replacement. The technique followed anterior decompression differed according to the way of reconstruction at each level and the patients were accordingly classified into three groups:

i. Group A (1-level fusion): where the anterior decompression was accomplished by single level cervical discectomy, and then insertion of cervical cage at this level.

ii. Group B (2-level fusion): where the anterior decompression was accomplished by double level cervical discectomy, and then insertion of cervical cage at both levels.

iii. Group C (hybrid construct): where the anterior decompression was in the form of one level cervical discectomy, followed by cage implantation at this level and another level cervical discectomy followed by insertion of cervical disc prosthesis at the same time. The former was filled with spongy bone.

\section{Age}

The ages in our patient population ranged from 30 to 50 years, with a mean of $40 \pm 5.9$ years (mean \pm standard deviation).

\section{Sex}

Eleven out of the twenty patients (55\%) were males, and 9/20 (45\%) were females.

\section{Occupation}

The occupation of the patients was found to be as follows:

Employees: 20/20 (100\%) patients

\section{Associated medical problems}

a) $4 / 20(20 \%)$ patients were hypertensive.

b) $3 / 20(15 \%)$ patients were diabetic.

c) In $16 / 20(80 \%)$ patients, there was no associated medical diseases.

Associated lumbar spine troubles: 3/20 (15\%) patients had associated degenerative findings in the lumbar spine, while $17 / 20(85 \%)$ were free of complaints in the lumbar area.

Smoking habits: $2 / 20(10 \%)$ patients were habitual smokers, while 18/30 (90\%) were non-smokers.

Duration of symptoms: The duration of preoperative symptoms ranged from 24 to 60 months (mean 31.75 months). The follow-up duration ranged from 1 to 12 months.

\section{Previous treatment}

All patients included in this series had had previous 
unsuccessful treatment in the form of non-steroidal antiinflammatory drugs and physiotherapy. Beside these forms of treatment, 10/20 (50\%) patients tried other forms of treatment:

A. $1 / 20(5 \%)$ patients received a local infiltration with steroids and analgesic, while $3 / 20(15 \%)$ patients wore a cervical collar for a certain period of time before presentation.

B. $2 / 20(10 \%)$ patients had had both local infiltration and a cervical collar.

Inclusion criteria: Degenerative disc disease within levels between C3-C7 at single or double level causing

a. Neck pain and/or brachialgia

b. Neurologic deficit (some patients included will have signs of myelopathy)

- $\quad$ Age between 18-70 years.

- Failure of conservative treatment for more than 6 weeks or with progressive pain/ neurologic deficit.

\section{Exclusion criteria:}

I. Marked cervical instability

a) Translation $>3 \mathrm{~mm}$ and/or

b) Segmental angulation $>110$ higher than adjacent levels.

II. Compromised vertebral bodies due to prior surgery or fracture at the affected level.

III. Patients with recurrent cervical disc disease.

IV. Ossification of the posterior longitudinal ligament or diffuse hyperostosis.

V. Unknown etiology for neck and/or arm pain.

VI. Metabolic bone disease

VII. Paget's disease.

VIII. Malignant bone diseases.

IX. Active infection.

\section{Patients and evaluation}

Twenty patients with degenerative disc disease were assigned to one of three groups of patients and treated by either:

1) Anterior cervical discectomy and single level fusion.

Or

2) Anterior cervical discectomy and double level fusion.

Or

3) Anterior cervical discectomy followed by fusion at one level and anterior cervical discectomy and implantation of disc prosthesis at another level at the same time.

\section{Preoperative assessment}

I. Clinical assessment:

- General condition and risk factors Diabetic, hypertensive, .etc

- Analysis of pain

a) Axial (origin, radiation, effect on neck motion, duration, and intensity using visual analogue scale).

b) Radicular (root affected, duration, and intensity using visual analogue scale).

c) Visual analogue scale is a pain rating scale which allows the patient to visually gauge the amount of pain along a solid $10-\mathrm{cm}$ line scale.

- Documentation of neurologic deficit

1) Sensory

2) Motor

3) Reflexes

4) Gait

5) Sphincteric disturbance

II. Radiologic assessment:

- Plain radiography:

Antero-posterior

Lateral: (neutral, flexion, extension)

- $\quad$ MRI cervical spine

III. Nerve conduction study was done to exclude peripheral compression neuropathy and to confirm radiculopathy in selected cases where double entrapment phenomena suspected.

IV. Laboratory investigation with routine laboratory checkup.

- $\quad \mathrm{CBC}$

- Renal function test

- $\quad$ Liver function test

- $\quad$ Bleeding profile

- $\quad$ Fasting and Random blood sugar

- $\quad$ ECG

- $\quad$ Serum alkaline phosphatase

- $\quad$ Serum calcium level

- Urine analysis (ex: urinary hydroxyproline increased in Paget's disease)

i. Clinical assessment: (Done immediate postoperative, 3 months, 12) 
- $\quad$ Analysis of pain

a) Axial (origin, radiation, effect on neck motion, duration, and intensity using visual analogue scale).

b) Radicular (root affected, duration, and intensity using visual analogue scale).

- Documentation of neurologic deficit
a) Sensory
b) Motor
c) Reflexes
d) Gait

ii. Functional outcome: was assessed according to Odom's criteria [6]. It was defined as:

1) Excellent in patients who had no complaints referable to cervical disc disease and were able to carry on their daily routines without any impairment.

2) Good outcome was defined as intermittent discomfort related to cervical disc disease which, however, did not significantly interfere with work.

3) Satisfactory outcome was defined as subjective improvement but limited physical activities.

4) Poor outcome included patients who did not improve or worsened after surgery.

iii. Patient satisfaction: with postoperative results, is evaluated using a patient satisfaction index (PSI). This index is a modified sub item of the North American Spine Society outcome questionnaire. It is scored as follows:

a) Very satisfied (surgery met my expectations).

b) Satisfied (I did not improve as much as hoped but would undergo the same operation for the same results).

c) Unsatisfied (surgery helped but I would not undergo the same operation for the same results).

d) Very unsatisfied (I am the same or worse than before surgery).

iv. Radiological outcome;

(Done immediate postoperative, 3 months, 6 months 12 month postoperatively)

\section{Plain X-rays of the cervical spine}

- Antero-posterior

- $\quad$ Lateral (neutral, flexion, and extension)

Done for evaluation of:

A. Cervical spine alignment

B. Cervical spine stability
C. Position of the implanted prosthesis

D. Maintenance of cervical motion at operated level in artificial disc group.

E. Assessment of global range of motion

F. Fusion of the operated level in case of hybrid cases.

Assessment of global range of motion (from C2 to C7) is done manually by measuring the difference, in flexion and extension, between an angle formed between a line parallel to the superior end plate of $\mathrm{C} 7$ and a line joining the anterior edge of the superior end plate of $\mathrm{C7}$ to the anterior edge of the inferior end plate of C2 Figure 1.

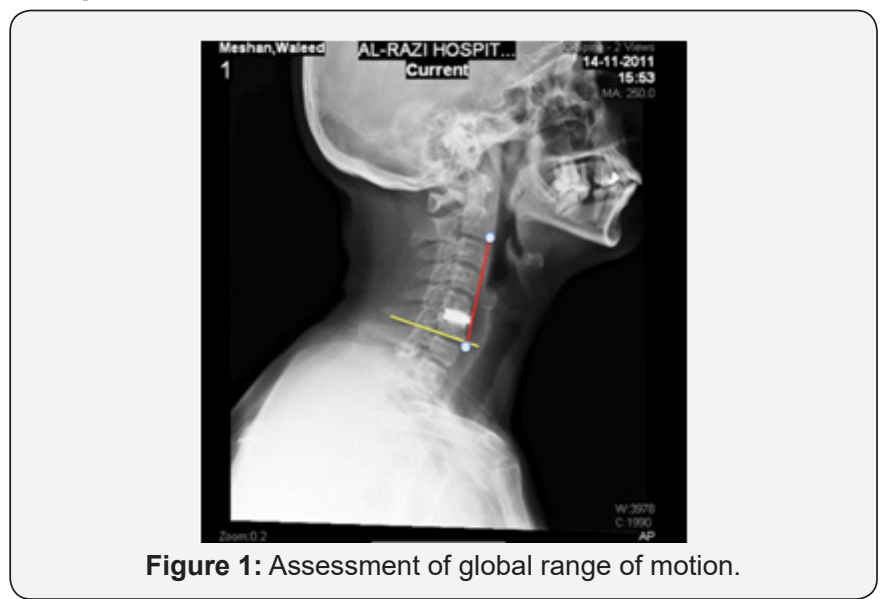

\section{MRI or CT of the cervical spine}

It is done for patients routinely and for patients not improving or with persistent preoperative complaint or any new neurologic deficit.

\section{Artificial cervical disc devices used in this study: Prestige LP}

\section{Methods of operative treatment}

Patient's Informed Consent: All patients have been informed about general complications of cervical spine surgery. Also, they were told that total disc replacement is an innovative technique with a lack of long-term results. All patients have also been informed about the risk of nerve and spinal cord injury and disturbances due to the access (indirect spinal cord contusion due to vigorous hammering on the chisel) or due to postoperative changes (e.g., implant luxation, extrusion, subsiding).

Anesthesia and Monitoring: Orotracheal intubation using a standard single lumen tube was done in all patients.

\section{Positioning and draping}

\section{Supine position}

- The patient's head was placed on a round foam headrest.

- A folded and rolled sheet was placed horizontally under the patient's shoulders to slightly hyperextend his or her neck while avoiding overextension. 


\section{Open Access Journal of Neurology \& Neurosurgery}

- $\quad$ Both arms were padded with foam arm pads and then tucked at the patient's sides with the palmar surfaces of the patient's hands against his or her body. The draw sheet was placed over the patient's arms and tucked under his or her body to keep the arms securely in place throughout the procedure.

- $\quad$ After tucking both arms, the patient's shoulders were pushed down, and a wide silk tape was used to secure the patient's shoulders and arms in position. The tape was placed the length of the arms from the shoulders to the fast end of the operating bed. This assisted in securing the patient's position, stretched the skin in the operative field, and allowed better intraoperative visualization of the lower cervical spine with radiographs.

- The patient's skin was cleansed with an iodine-alcohol solution from the chin to the upper chest, after which, sterile towels were placed to square off the surgical area, which was finally covered with an OP-Site.

\section{Surgical approach}

- A transverse right-sided approach centered over the medial border of the sternocleidomastoid muscle was made to expose the symptomatic level.

- A standard anterior approach to the cervical spine is performed. Once the desired cervical levels are visualized using fluorography before and during approach, it is important to mark the midline.

- The frontal midline can be identified by using the anatomic landmarks and fluoroscopy before placing a midline marker (Figure 2).

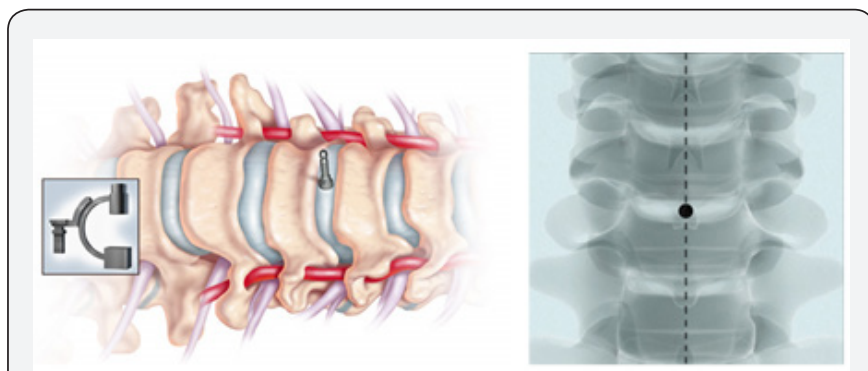

Figure 2: Midline confirmation and Placement of the midline marker.

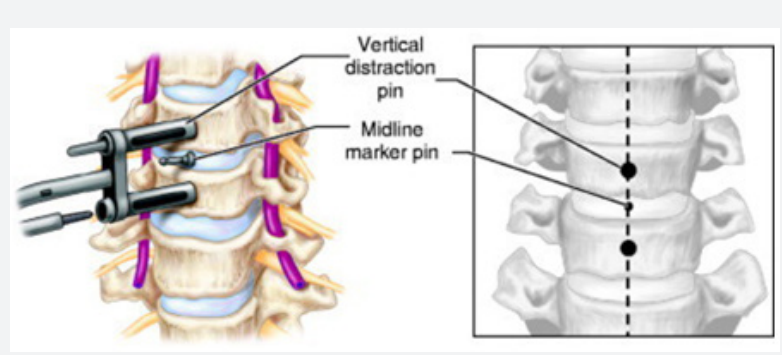

Figure 3: (A) The double-barrel guide and insertion of distraction pins.
All anterior osteopyhtes need to be removed. Once the midline has been identified and confirmed with an AP fluoroscopic image, a double-barrel guide is used for insertion of distraction pins into the vertebral bodies at the appropriate angle. Lateral fluoroscopy can be used to ensure that pins do not extend into the spinal canal and are parallel to the inferior end plates of the vertebral bodies; an AP fluoroscopic image is used to confirm frontal midline position of distraction pins (Figure 3a \&b).

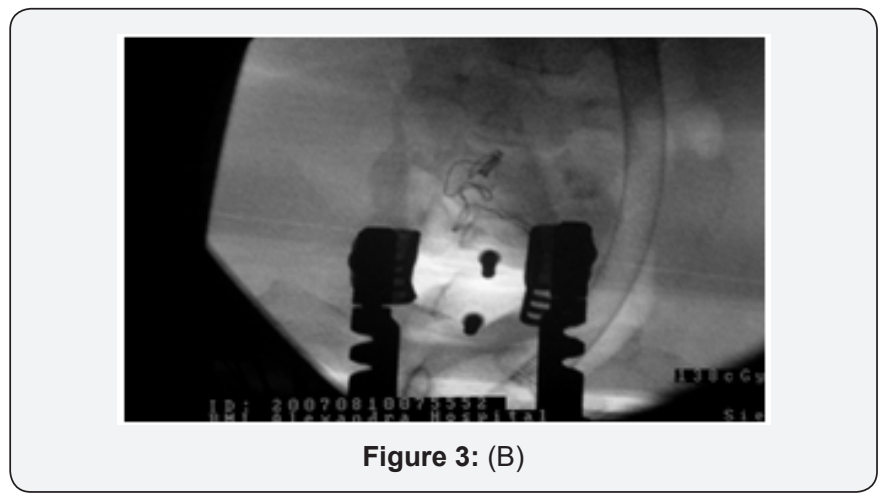

Statistical Methodology

The main outcome measure was pain intensity (Neck pain and Arm pain) over a 12-month period. Other outcome measures were: Duration of operation, length of hospital stay, and complications. The overall effectiveness of the treatment was assessed as using PSI and Odom's Scale. The mean improvement in pain amongst the treatment groups were first compared with an analysis of variance followed by multiple comparisons tests based on the Bonferroni method. Multiple linear regressions weren't used to analyse the effect of the treatment since there were no statistically significant baseline characteristics.

\section{Baseline patients' demographic data}

Table 1: Age distribution in treatment groups.

\begin{tabular}{|c|c|c|c|c|}
\hline & Total & $\begin{array}{c}\text { 1-level } \\
\text { group }\end{array}$ & $\begin{array}{c}\text { 2-level } \\
\text { group }\end{array}$ & $\begin{array}{c}\text { Hybrid } \\
\text { group }\end{array}$ \\
\cline { 1 - 4 } $\begin{array}{c}\text { No of } \\
\text { patients }\end{array}$ & 20 & 13 & 5 & 2 \\
\cline { 1 - 4 } AGE/Years & \multirow{2}{*}{$40(5.9)$} & $40(6.6)$ & $37.8(5.2)$ & $45(7.1)$ \\
\cline { 1 - 3 } Mean(SD) & &
\end{tabular}

Table 2: Sex distribution in treatment groups.

\begin{tabular}{|c|c|c|c|c|}
\hline Sex & $\begin{array}{c}\text { No. of } \\
\text { cases }\end{array}$ & $\begin{array}{c}\text { 1-level } \\
\text { group }\end{array}$ & $\begin{array}{c}\text { 2-level } \\
\text { group }\end{array}$ & $\begin{array}{c}\text { Hybrid } \\
\text { group }\end{array}$ \\
\hline $\begin{array}{c}\text { No of } \\
\text { patients }\end{array}$ & 20 & 13 & 5 & 2 \\
\hline Male n (\%) & 11 & $7(53.8)$ & $3(60)$ & $1(50)$ \\
\hline $\begin{array}{c}\text { Female } \\
\text { (\%) }\end{array}$ & 9 & $6(46.2)$ & $2(40)$ & $1(50)$ \\
\hline
\end{tabular}

Mean Age for All groups were, $=40 \pm 5.9$ Years [Range: $30-50$ Years], the mean age \pm SD for group of single level was $40 \pm 6.6$; double level was $37.8 \pm 5.5$ and $45 \pm 7.1$ for the hybrid group (Table 1). There were 13 patients in single level group, 5 patients 
in double level group and 2 patients in hybrid group, 7 males and 6 females in the single level group, 3 males and 2 females in the double level group, and one male and one female in the hybrid group (Table 2) (Figure 4).

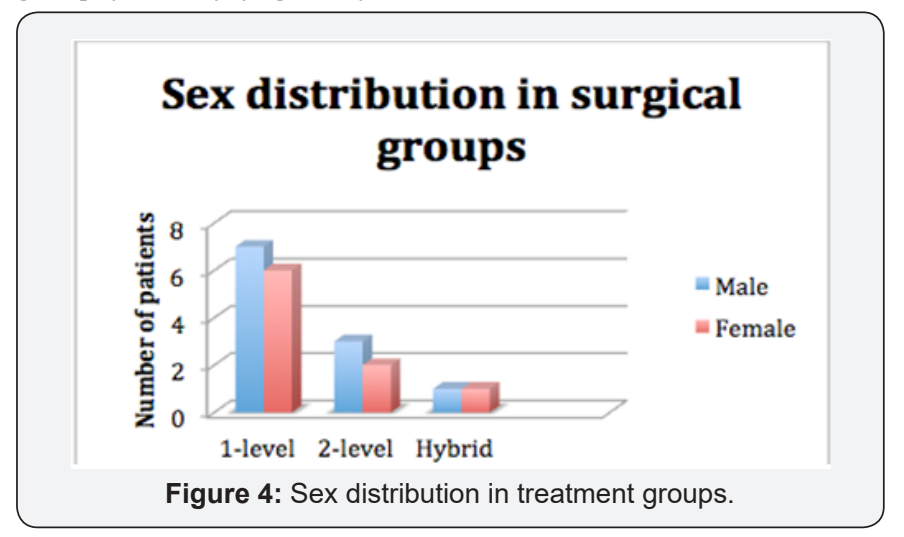

\section{Baseline patients' clinical data}

Table 3: Patients' past medical history.

\begin{tabular}{|c|c|c|c|}
\hline Medical History & $\begin{array}{c}\text { 1-level } \\
\text { group }\end{array}$ & $\begin{array}{c}\text { 2-level } \\
\text { group }\end{array}$ & $\begin{array}{c}\text { Hybrid } \\
\text { group }\end{array}$ \\
\hline Total No of patients & 13 & 5 & 2 \\
\hline \multicolumn{4}{|c|}{ Medical problems } \\
\hline Number (\%) & $3(23.1)$ & $1(20)$ & $1(50)$ \\
\hline \multicolumn{4}{|c|}{ Smoking } \\
\hline Yes (\%) & $2(15.4)$ & $(0) 0$ & $0(0)$ \\
\hline
\end{tabular}
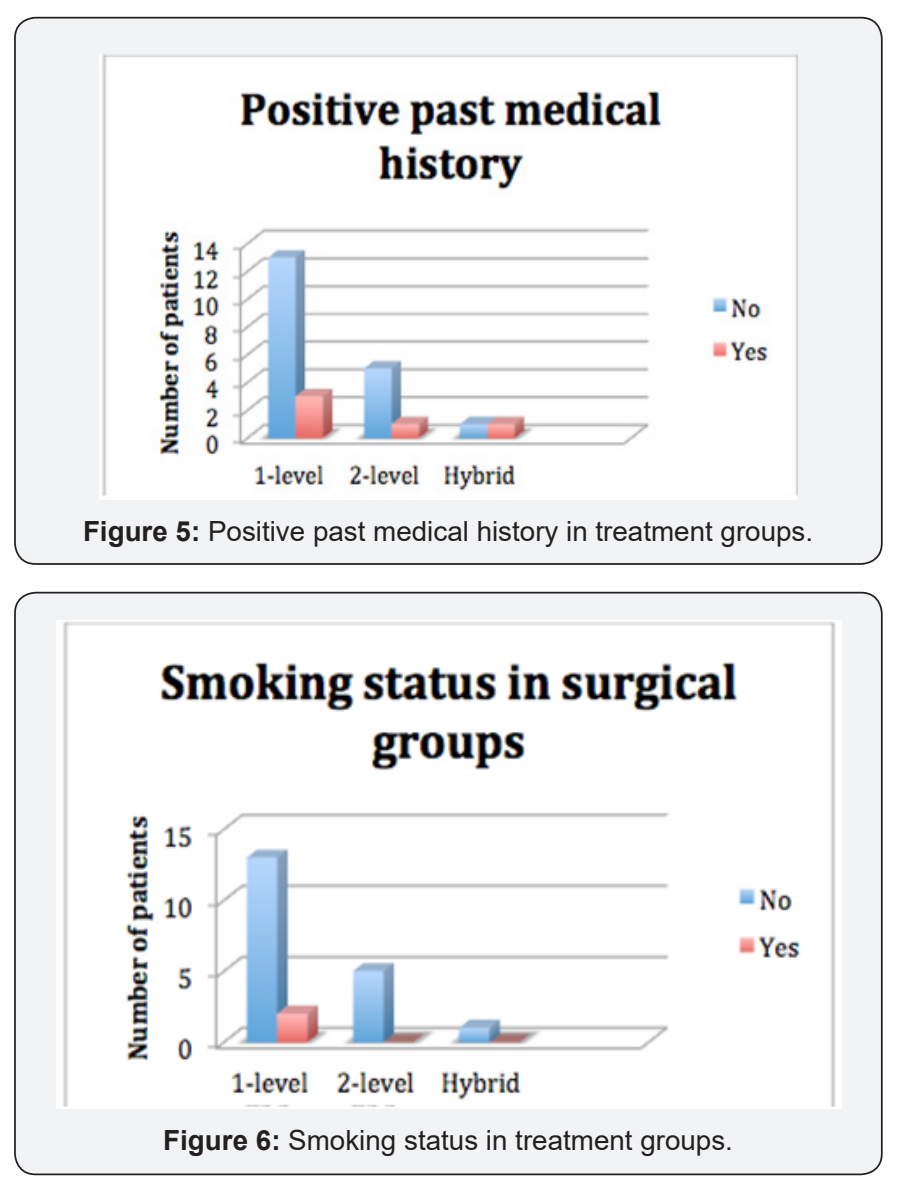

Regarding the Past medical history, there were 3 patients in the single level group with medical problems (1 was diabetic, 1 was hypertensive, and 1 was diabetic and hypertensive), while in the double level group there was 1 patient with past medical problems (diabetic and hypertensive) and there was 1 patient in the hybrid group with medical problems (diabetic and hypertensive) (Table 3). Regarding the smoking habit there was 2 smokers (15.4\%) in the single level group, while in the double level and hybrid groups there were no smokers (Figure 5\&6).

\section{Patients' clinical features}

Table 4: Patients' clinical features.

\begin{tabular}{|c|c|c|c|}
\hline Variable & 1-level group & 2-level group & Hybrid group \\
\hline Total No of patients & 13 & 5 & 2 \\
\hline \multicolumn{4}{|c|}{ Radiculopathy } \\
\hline Number (\%) & $13(100)$ & $5(100)$ & $2(100)$ \\
\hline \multicolumn{4}{|c|}{ Myelopathy } \\
\hline Number (\%) & $0(0)$ & $0(0)$ & $0(0)$ \\
\hline \multicolumn{4}{|c|}{ Axial neck pain } \\
\hline Number (\%) & $5(38.5)$ & $4(80)$ & $2(100)$ \\
\hline \multicolumn{4}{|c|}{ Duration of Symptoms/months } \\
\hline Mean (SD) & $31.8(10.6)$ & $31.4(4.9)$ & $32(11.3)$ \\
\hline
\end{tabular}

Table 5: Preoperative neck and arm VAS.

\begin{tabular}{|c|c|c|c|}
\hline VAS & 1-level group & 2-level group & Hybrid group \\
\hline \multicolumn{4}{|c|}{ Neck Pain VAS } \\
\hline $\mathrm{N}$ & 13 & 5 & 2 \\
\hline Mild Pain n (\%) & $1(7.7)$ & $0(0)$ & $0(0)$ \\
\hline $\begin{array}{c}\text { Moderate Pain } \\
\mathrm{n}(\%)\end{array}$ & $7(53.8)$ & $3(60)$ & $0(0)$ \\
\hline $\begin{array}{c}\text { Severe Pain } \mathrm{n} \\
(\%)\end{array}$ & $5(38.5)$ & $2(40)$ & $2(100)$ \\
\hline \multicolumn{4}{|c|}{ Arm Pain VAS } \\
\hline $\mathrm{N}$ & 13 & 5 & 2 \\
\hline Mild Pain n (\%) & $3(23.1)$ & $4(80)$ & $0(0)$ \\
\hline $\begin{array}{l}\text { Moderate Pain } \\
\mathrm{n}(\%)\end{array}$ & $9(69.2)$ & $0(0)$ & $0(0)$ \\
\hline $\begin{array}{c}\text { Severe Pain n } \\
(\%)\end{array}$ & $1(7.7)$ & $1(20)$ & $2(100)$ \\
\hline
\end{tabular}

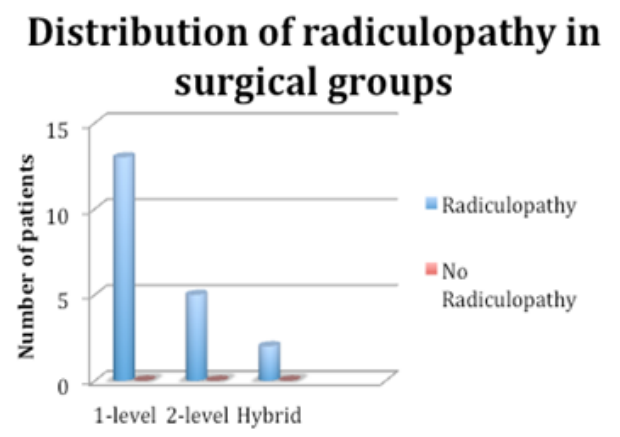

Figure 7: Distribution of radiculopathy in surgical groups. 


\section{Distribution of axial neck pain in surgical groups}

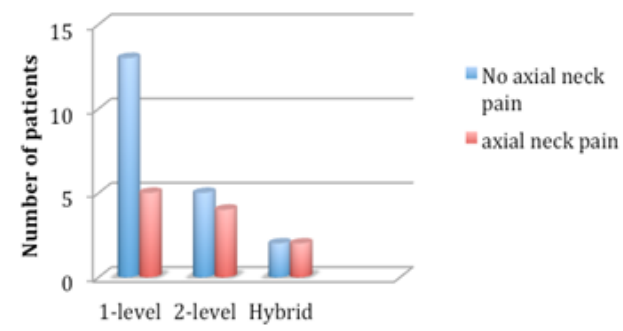

Figure 8: Distribution of axial neck pain in surgical groups.

\section{Distribution of pre-operative neck pain}

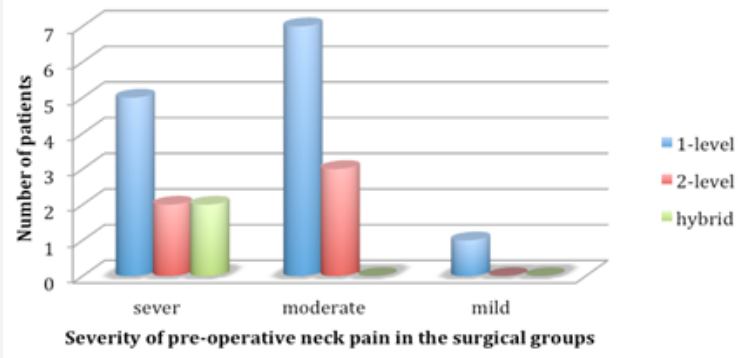

Figure 9: Distribution of pre-operative neck pain in surgical groups.

\section{Distribution of pre-operative arm pain}

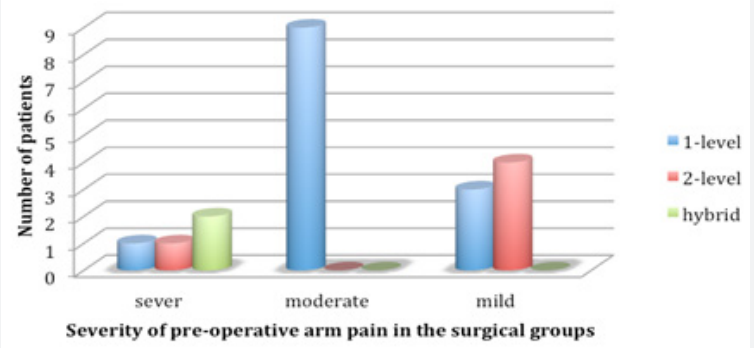

Figure 10: Distribution of pre-operative arm pain in surgical group.

As regards the pre-operative clinical presentations, 13 $(100 \%)$ patients in the single level group, $5(100 \%)$ patients in the double level group, and $2(100 \%)$ patients in the hybrid group had radiculopathy, and $5(38.5 \%)$ patients in single level group, $4(80 \%)$ patients in the double level group versus 2 $(100 \%)$ in the hybrid group had axial neck pain (Table 4$)$. The mean duration of symptoms was 31.8 months for single level group, 31.4 months for double level group and 32 months in hybrid group. The duration of symptoms ranged from 20 to 60 months in the single level group, while it ranged from 27 to 40 months in the double level group and it ranged from 24 to 40 in the hybrid group (Figure 7\&8) (Table 5). 7(53.8\%) of patients in single level group had Moderate neck Pain versus $3(60 \%)$ in double level group and 0 in hybrid group, while as regards arm pain $9(69.2 \%)$ of patients in the single level group had moderate arm pain versus $1(7.7 \%)$ in the double level group and $2(100)$ in the hybrid group had sever arm pain (Figure $9 \& 10$ ).

\section{Baseline radiological data}

Table 6: Patients' baseline radiological data.

\begin{tabular}{|c|c|c|c|}
\hline Disc Level & 1-level group & 2-level group & Hybrid group \\
\hline $\mathbf{N}$ & 13 & 5 & 2 \\
\hline C3-4 n (\%) & 0 & 0 & 0 \\
\hline C4-5 n (\%) & $4(30.8)$ & $5(100)$ & $2(100)$ \\
\hline C5-6 n (\%) & $9(69.2)$ & $5(100)$ & $2(100)$ \\
\hline C6-7 n (\%) & 0 & 0 & 0 \\
\hline
\end{tabular}

The most common operated level was C5-6, where it include 9 patients $(69.2 \%)$ in the single level group, 5 patients $(100 \%)$ in double level group and 2 patients $(100 \%)$ in the hybrid group, followed by C4-5 level including 4 patients (30.8\%) in the single level group, 5 patients (100\%) in the double level group and 2 patients $(100 \%)$ in the hybrid group (Table 6) (Figure 11). The mean operative time in the single level group was 71.5 minutes, while in the double level group it was 110 minutes and in the hybrid group it was 105 minutes. Regarding the mean duration of hospital stay it was 2.4 days in the single level group while it was 3.8 days in the double level group and 4 days in the hybrid group.

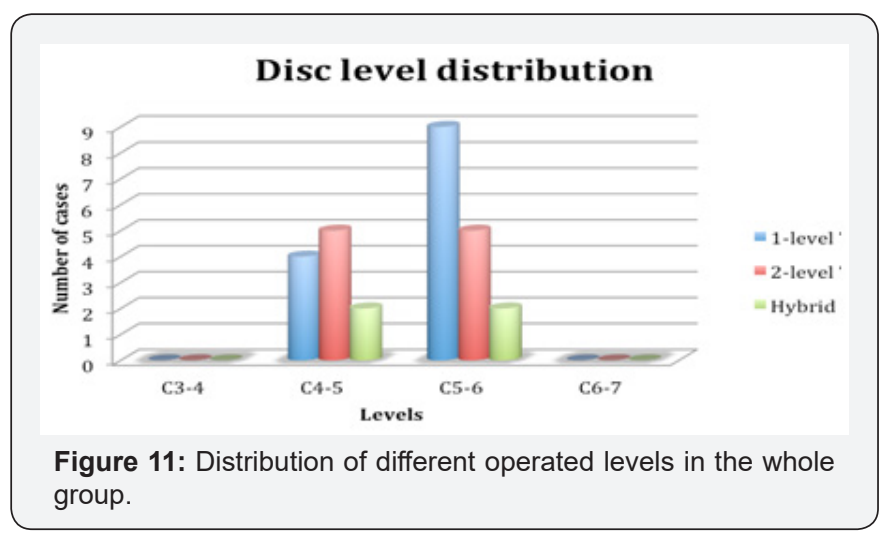

\section{Outcome in all groups}

Table 7: Duration of operations in minutes.

\begin{tabular}{|c|c|c|c|}
\hline $\begin{array}{c}\text { Duration of } \\
\text { Operation/Minutes }\end{array}$ & $\begin{array}{c}\text { 1-level } \\
\text { group }\end{array}$ & $\begin{array}{c}\text { 2-level } \\
\text { group }\end{array}$ & $\begin{array}{c}\text { Hybrid } \\
\text { group }\end{array}$ \\
\hline $\mathbf{N}$ & 13 & 5 & 2 \\
\hline Mean (SD) & $71.5(23.1)$ & $110(9.4)$ & $105(7.1)$ \\
\hline
\end{tabular}

Table 8: Duration of hospital stay.

\begin{tabular}{|c|c|c|c|}
\hline $\begin{array}{c}\text { Length of Hospital } \\
\text { Stay/Days }\end{array}$ & $\begin{array}{c}\text { 1-level } \\
\text { group }\end{array}$ & $\begin{array}{c}\text { 2-level } \\
\text { group }\end{array}$ & $\begin{array}{c}\text { Hybrid } \\
\text { group }\end{array}$ \\
\hline $\mathrm{N}$ & 13 & 5 & 2 \\
\hline Mean (SD) & $2.4(0.5)$ & $3.8(0.4)$ & $4(0)$ \\
\hline
\end{tabular}

The mean operative time in the single level group was 71.5 minutes, while in the double level group it was 110 minutes and in the hybrid group it was 105 minutes. Regarding the mean duration of hospital stay it was 2.4 days in the single level group while it was 3.8 days in the double level group and 4 days in the hybrid group. In this study 4 patients underwent 4 surgical 


\section{Open Access Journal of Neurology \& Neurosurgery}

procedures, 2 patients in the single level group while one patient in the double level group and one patient in the hybrid group, the four patients had carpal tunnel release during the follow up period. For the follow-up duration it ranged from 1 month to 12 months (mean 8.6) in the single level group, while it ranged from 9 months to 12 months (mean 10.4) in the double level group and 9 months in the hybrid group (Tables 7-11).

Table 9: Number of operations in all groups.

\begin{tabular}{|c|c|c|c|}
\hline Variable & 1-level group & $\begin{array}{c}\text { 2-level } \\
\text { group }\end{array}$ & $\begin{array}{c}\text { Hybrid } \\
\text { group }\end{array}$ \\
\hline Total No of patients & 13 & 5 & 2 \\
\hline Number of Operations & 2 & 1 & 1 \\
\hline Percent & $15.40 \%$ & $20 \%$ & $50 \%$ \\
\hline
\end{tabular}

Table 10: Duration of follow-up.

\begin{tabular}{|c|c|c|c|}
\hline Variable & 1-level group & 2-level group & Hybrid group \\
\hline \multicolumn{4}{|c|}{ Duration of Follow-up/months } \\
\hline $\mathrm{n}$ & 13 & 5 & 2 \\
\hline Mean (SD) & $17.6(6.5)$ & $20.4(3.3)$ & $18(0)$ \\
\hline
\end{tabular}

Table 11: VAS neck and arm at 12 months.

\begin{tabular}{|c|c|c|c|}
\hline Variable & 1-level group & 2-level group & Hybrid group \\
\hline \multicolumn{4}{|c|}{ VAS Neck at 12 Months post-op } \\
\hline n & $\mathbf{1 3}$ & $\mathbf{5}$ & $\mathbf{2}$ \\
\hline Mild Pain: n (\%) & $12(92.3)$ & $3(60)$ & $2(100)$ \\
\hline Moderate Pain: n (\%) & - & $1(20)$ & - \\
\hline Severe Pain: n (\%) & $1(7.7)$ & $1(20)$ & - \\
\hline \multicolumn{5}{|c|}{ VAS Arm at 12 Months post-op } \\
\hline n & $\mathbf{1 3}$ & $\mathbf{5}$ & $\mathbf{2}$ \\
\hline Mild Pain: n (\%) & $11(84.6)$ & $4(80)$ & - \\
\hline Moderate Pain: $\mathrm{n}(\%)$ & $2(15.4)$ & $1(20)$ & - \\
\hline Severe Pain: $\mathrm{n}(\%)$ & - & - & \\
\hline
\end{tabular}

\section{At the 12-month follow up}

Regarding neck pain: 12 patients (92.3\%) had mild pain, and 1 patient $(7.7 \%)$ had severe pain in the single level group versus 3 patients $(60 \%)$ had mild pain, one patient $(40 \%)$ had moderate pain and one patient (20\%) had severe pain in the double level group, and all patients in the hybrid group had mild pain.

Regarding arm pain: 11 patients $(84.6 \%)$ had mild pain and 2 patient (15.4\%) had moderate pain in the single level group, versus 4 patients (80\%) had mild pain and 1 patient (20\%) had moderate pain in the double level group and all patients in the hybrid group had mild pain, no patients had severe pain among all groups.

\section{Mean improvement in Vas (Post-0p At 12 Months Vs Pre-0p)}

Most of patients in the three groups were suffering from moderate to severe arm and neck pain, in the post-operative follow-up most of patients had mild to moderate pains, only 2 patients in single and double level groups had severe neck pain and no patients among all group had any severe arm pain. The mean decrease in VAS neck was 3.2 in the single level group versus 2.8 in the double level group and 4.5 in the hybrid group. The mean decrease in VAS arm was 3.8 in the single level group versus 3.8 in the double level group and 5.5 in the hybrid group. There were 2 complications in this study, one (7.7\%) in the single level group and one $(20 \%)$ in the double level group (Tables 1215) (Figures 12\&13).

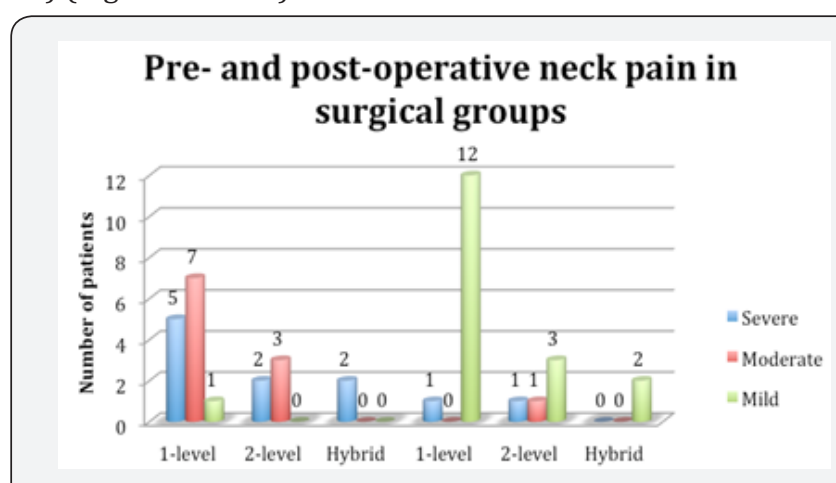

Figure 12: Comparing pre- and post-operative neck pain in surgical groups.

\section{Pre- and post-operative arm pain in surgical groups}

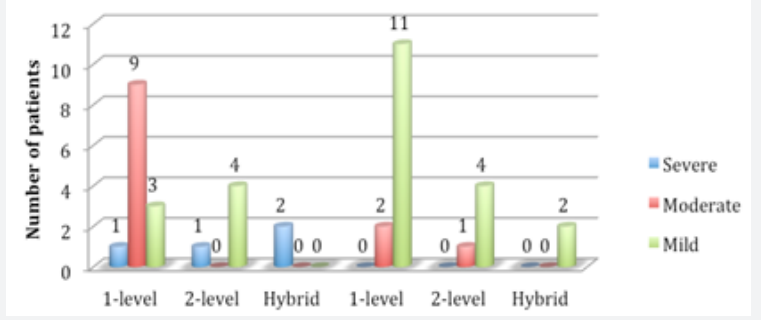

Figure 13: Comparing pre- and post-operative arm pain in surgical group.

Table 12: Change in VAS in all groups.

\begin{tabular}{|c|c|c|c|c|c|c|}
\hline \multirow{2}{*}{ Treatment groups } & \multicolumn{7}{|c|}{ 1-level group (n=13) } & \multicolumn{2}{c|}{ 2-level group (n=5) } & \multicolumn{2}{c|}{ Hybrid group (n=2) } \\
\cline { 2 - 7 } & Pre-op & Post-op (12 months) & Pre-op & Post-op (12 months) & Pre-op & Post-op (12 months) \\
\hline \multicolumn{7}{|c|}{ Arm Pain } \\
\hline Mild Pain: n (\%) & $1(7.7)$ & $12(92.3)$ & $0(0)$ & $3(60)$ & $0(0)$ & $2(100)$ \\
\hline Moderate Pain: $n(\%)$ & $7(53.8)$ & - & $3(60)$ & $1(20)$ & $0(0)$ & - \\
\hline Severe Pain: n (\%) & $5(38.5)$ & $1(7.7)$ & $2(40)$ & $1(20)$ & $2(100)$ & - \\
\hline \multicolumn{7}{|c|}{}
\end{tabular}




\section{Open Access Journal of Neurology \& Neurosurgery}

\begin{tabular}{|c|c|c|c|c|c|c|}
\hline Mild Pain: $\mathrm{n}(\%)$ & $3(23.1)$ & $11(84.6)$ & $4(80)$ & $4(80)$ & - & $2(100)$ \\
\hline Moderate Pain: $\mathrm{n}(\%)$ & $9(69.2)$ & $2(15.4)$ & - & $1(20)$ & - & - \\
\hline Severe Pain: $\mathrm{n}(\%)$ & $1(7.7)$ & - & $1(20)$ & - & $2(100)$ & - \\
\hline
\end{tabular}

Table 13: Mean decrease in VAS neck.

\begin{tabular}{|c|c|c|c|}
\hline Variable & $\begin{array}{c}\text { 1-level group } \\
(\mathbf{n = 1 3 )}\end{array}$ & $\begin{array}{c}\text { 2-level group } \\
(\mathbf{n}=\mathbf{5})\end{array}$ & $\begin{array}{c}\text { Hybrid group } \\
(\mathbf{n = 2})\end{array}$ \\
\hline $\begin{array}{c}\text { Pre-operative } \\
\text { VAS neck }\end{array}$ & 7 & 7.2 & 8 \\
\hline $\begin{array}{c}\text { post-operative } \\
\text { VAS neck }\end{array}$ & 3.8 & 4.4 & 3.5 \\
\hline $\begin{array}{c}\text { Decrease in } \\
\text { VAS Neck }\end{array}$ & $3.2 \pm 1.6$ & $2.8 \pm 1.8$ & $4.5 \pm 1.9$ \\
\hline
\end{tabular}

Table 14: Mean decrease in VAS arm.

\begin{tabular}{|c|c|c|c|}
\hline Variable & $\begin{array}{c}\text { 1-level group } \\
(\mathbf{n = 1 3 )}\end{array}$ & $\begin{array}{c}\text { 2-level group } \\
(\mathbf{n}=\mathbf{5})\end{array}$ & $\begin{array}{c}\text { Hybrid group } \\
(\mathbf{n}=\mathbf{2})\end{array}$ \\
\hline $\begin{array}{c}\text { Pre-operative } \\
\text { VAS arm }\end{array}$ & 6.8 & 6.6 & 7.5 \\
\hline $\begin{array}{c}\text { post-operative } \\
\text { VAS arm }\end{array}$ & 3 & 2.8 & 2 \\
\hline $\begin{array}{c}\text { Decrease in } \\
\text { VAS Arm }\end{array}$ & $3.8 \pm 1.4$ & $3.8 \pm 1.6$ & $5.5 \pm 1.5$ \\
\hline
\end{tabular}

Table 15: Complications in all groups.

\begin{tabular}{|c|c|c|c|}
\hline Complications & 1-level group & 2-level group & Hybrid group \\
\hline $\begin{array}{c}\text { Total } \mathrm{N}^{\circ} \text { of } \\
\text { patients }\end{array}$ & 13 & 5 & 2 \\
\hline Number (\%) & $2(7.7)$ & $1(20)$ & 0 \\
\hline
\end{tabular}

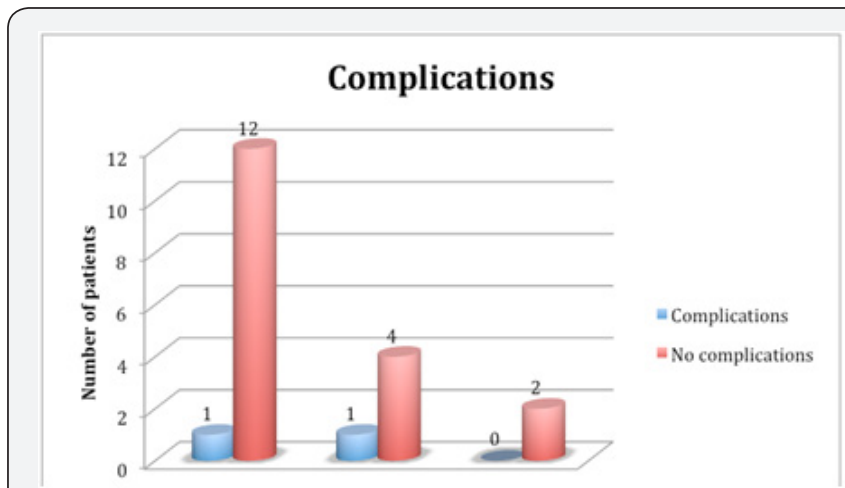

Figure 14: Complications in surgical groups.

In the single level group 1 patient had removal of prosthesis due to device failure and hypermobility. In the double level group, one patient had temporary dysphagia and dysphonia. As regard patient satisfaction; 9 patients (69.2\%) were very satisfied in the single level group versus 3 patients (60\%) In the double level group and 2 patients $(100 \%)$ in the hybrid group, while there were 3 patients $(23.1 \%)$ who were satisfied in the single level group and 1 patient (20\%) In the double level group, finally only one patient was unsatisfied in the single level group and 1 patient in the double level group. Regarding the functional outcome 9 patients $(69.2 \%)$ had excellent outcome in the single level group versus 3 patients (60\%) In the double level group and 2 patients $(100 \%)$ in the hybrid group, while there were 3 patients $(23.1 \%)$ who had good outcome in the single level group and 1 patient (20\%) In the double level group, finally only one patient in the single level group and 1 patient in the double level group who had satisfactory outcome(Figure 14) (Tables 16 \& 17).

Table 16: Patient satisfaction index.

\begin{tabular}{|c|c|c|c|}
\hline \multicolumn{4}{|c|}{ Patients' Satisfaction } \\
\hline VARIABLE & $\begin{array}{c}\text { 1-level } \\
\text { group }\end{array}$ & $\begin{array}{c}\text { 2-level } \\
\text { group }\end{array}$ & $\begin{array}{c}\text { Hybrid } \\
\text { group }\end{array}$ \\
\hline Total No of patients & 13 & 5 & 2 \\
\hline Very Satisfied: $\mathrm{n}(\%)$ & $9(69.2)$ & $3(60)$ & $2(100)$ \\
\hline Satisfied: $\mathrm{n}(\%)$ & $3(23.1)$ & $1(20)$ & 0 \\
\hline Unsatisfied: $\mathrm{n}(\%)$ & $1(7.7)$ & $1(20)$ & 0 \\
\hline
\end{tabular}

Table 17: Functional outcome (Odom's scale).

\begin{tabular}{|c|c|c|c|}
\hline Variable & 1-level group & 2-level group & Hybrid group \\
\hline \multicolumn{4}{|c|}{ Odom`s scale } \\
\hline Excellent & $9(69.2)$ & $3(60)$ & $2(100)$ \\
\hline Good & $3(23.1)$ & $1(20)$ & 0 \\
\hline Satisfactory & $1(7.7)$ & $1(20)$ & 0 \\
\hline
\end{tabular}

\section{Discussion}
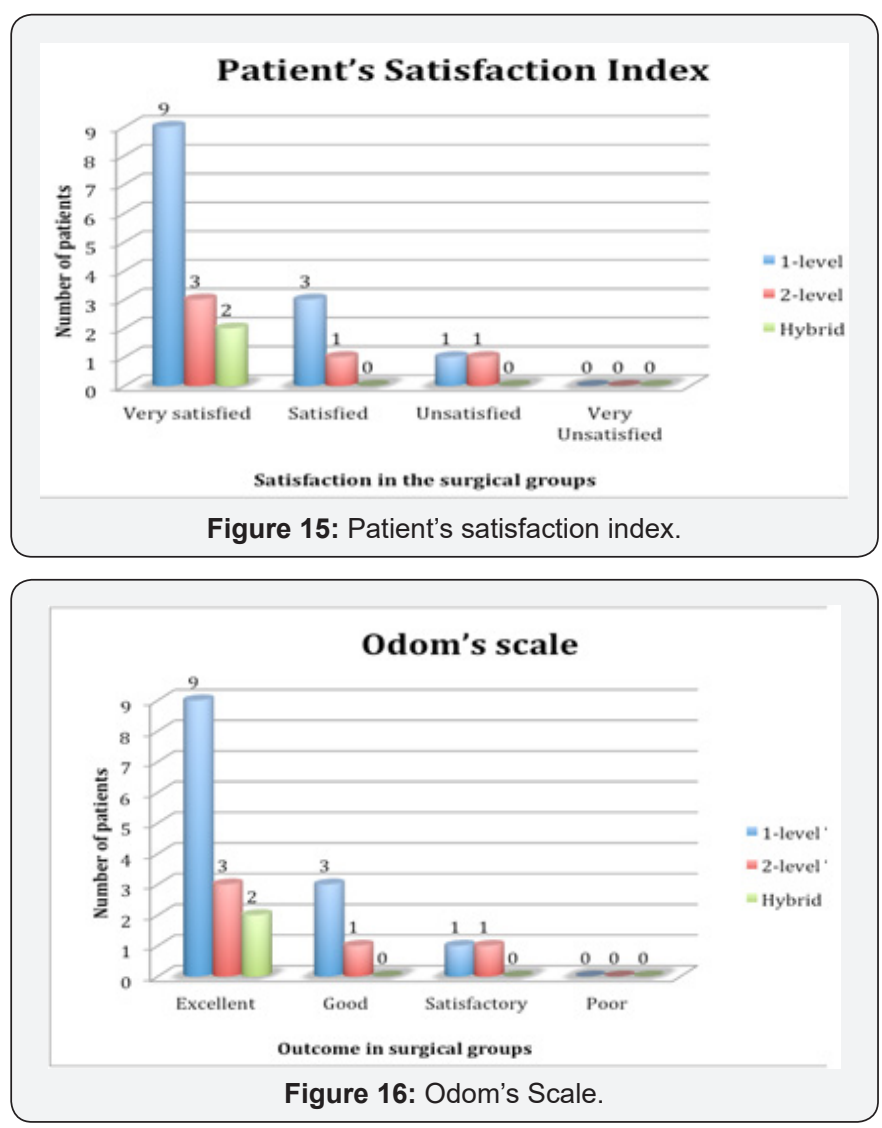
Cervical spine is unique in its biomechanics with a complex, wide range, and coupled motion aiming at providing a freedom of movement of the head in respect to the trunk while maintaining stability and protection to the neural structures. Degenerative disc disease results in three major manifestations of cervical disc herniation, depending on whether there is compression of a cervical nerve root or the spinal cord: neck pain, radiculopathy and cervical myelopathy. Diagnosis is achieved by thorough clinical assessment, plane radiography, MRI scans, and neurophysiological studies in selected cases. Surgical treatment of diseases affecting the anterior cervical spine was not safe and effective until 1950s when by Robinson and Smith, Cloward, Bailey and Bagley established the nowpopular anterior approach. Surgical management depends on neural decompression followed by reconstruction of the motion segment. Anterior cervical discectomy and fusion is considered the gold standard surgical management for degenerative cervical disc disease for many decades. But concerns regarding adjacent level accelerated degeneration, beside known complications due to fusion as symptomatic nonunion and donor site complications, raised the expectations to a novel technique to deal with the degenerated cervical motion segment following anterior discectomy [6,7] (Figures 15\&16).

Cervical disc replacement is a new treatment modality alternative to fusion; aiming to preserve motion after discectomy. The rationale for arthroplasty is that by maintaining motion, adjacent segment degeneration may be avoided. Other benefits include more rapid recovery and maintenance of function. Early results are encouraging, with success equal to or better than fusion with rare mechanical failures [8].

Cervical arthroplasty prostheses should aim to maintain the normal range and type of intervertebral segmental motion while transmitting axial loading forces from the vertebral body above to the one below [9].

Hypermobility is an indicator of increased stresses on adjacent segments following fusion. Many authors documented increased mobility in adjacent segments after cervical fusion [10-18]. Chronically elevated intradiscal pressures lead to deleterious metabolic degenerative changes followed by progressive adjacent level disease. This is because the cervical intervertebral disc is an avascular structure and nutrient exchange is primarily dependent on diffusion and osmotic pressure gradients [19]. Many investigators recorded increased intradiscal pressure following cervical fusion (as an indicator of increased stresses) $[13,18,19]$.

\section{Patients' demographics}

This study revealed that Mean Age for the three groups was $=40$ Years [Range: $30-50$ Years], the mean age for group of single level fusion was 40 ; double level g was 37.8 and 45 for the hybrid group of fusion was 46.8 and 48.5 for the artificial disc group. Which are comparable to other related studies in literatures [5,20,21]. Regarding the Three studied groups, the single level group showed male predominance (53.8\% males), while the double level group showed also male predominance ( $60 \%$ males) and the fusion group showed equal sex distribution (50\% each).

\section{Surgical strategy}

Single and double level disc disease are only included in this study, The most common operated level was C5-6; it represents $69.2 \%$ in the single level group, $100 \%$ in double level group and $100 \%$ in the hybrid group, followed by $\mathrm{C} 4-5$ level; it represents $30.8 \%$ in the single level group, $100 \%$ in the double level group and $100 \%$ in the hybrid group. This goes nearly with all the related studies, as Ryu et al. [22] stated that the most common operated levels were C5-6 (51\%). while in Seok Woo Kim et al. [21] C5/6 represented $61.5 \%$ in the artificial disc group, followed by C6-7 level including $21 \%$ in the artificial disc group. In Sekhon et al. [21], they stated that the frequency of C5-6 was $88 \%$. This prevalence can be explained by the concentration of forces at that level during neck flexion, or the decrease of canal diameter in relation to the cord diameter that makes this level more sensitive to disc prolapsed [23]. Standard anterior decompression was done followed by insertion of cervical cage, a variety of implant types sizes were used according to patients` varying anatomy, while in the hybrid group zero-profile implant for stand-alone anterior cervical interbody fusion were used. The mean operative time in the single level group was 71.5 minutes, while in the double level group it was 110 minutes and in the hybrid group it was 105 minutes. Rick C Sasso et al. [4] stated that it was 70 minutes for the fusion group while it took 105 minutes in the artificial disc group, which was longer than our study. For the follow-up duration it ranged from 1 month to 12 months (mean 8.6) in the single level group, while it ranged from 10 months to 12 months (mean 10.4) in the double level group and 9 months in the hybrid group. All these are comparable with other studies.

\section{Clinical outcome}

Regarding the clinical picture, the most common presentation was radiculopathy, $100 \%$ of patients in all groups had radiculopathy versus $38.5 \%$ patients in single level group, $80 \%$ patients in the double level group versus $100 \%$ in the hybrid group had axial neck pain. That was merely similar to that stated by other investigators. Seok Woo Kim et al. [21] reported in their series $92 \%$ patients in the artificial disc group had radiculopathy. In Lafuente J et al. [24], 80\% had radiculopathy.

Clinical outcome is compared between the three groups regarding:

1) Neck and arm pain

2) Functional outcome

3) Patient satisfaction

In this study all patients showed improvement in neck and arm pain, for the neck pain; mean decreased from 7 to 3.8 
in the single level group while it decreased from 7.2 to 4.4 in the double level group and from 8 to 3.5 in the hybrid group. For the arm pain; mean decreased from 6.8 to 3 in the single level group while it decreased from 6.6 to 2.8 in the double level group and from 7.5 to 2 in the hybrid group. All patients showed postoperative improvement in neurologic deficit that was more rapid in the sensory deficit. Improvements of arm pain (radiculopathy) and in neurologic deficit are directly related to the adequacy of decompression. Thus, improvements in arm pain (radiculopathy) and in neurologic deficit in the three operated groups are similar to each other as all shares the same technique.

Regarding the functional outcome according to Odom's criteria, in the single level group $92.3 \%$ of patients had excellent and good outcome, while the double level group $80 \%$ of patients had excellent and good outcome and in the hybrid group 100\% of patients had excellent outcome. There was no significant statistical difference between groups. All these are comparable and agreed with results of other studies. As regard patient satisfaction; $69.2 \%$ were very satisfied in the single level group versus $60 \%$ In the double level group and $100 \%$ in the hybrid group, while there were $23.1 \%$ who were satisfied in the single level group and $20 \%$ In the double level group, finally only one patient was unsatisfied in the single level group and 1 patient in the double level group. In the single-level study $86 \%$ of patients evaluated at 1-year follow-up Odom's scale was excellent, While In the bi-level study $82 \%$ of patients evaluated at 1 year followup Odom's scale was excellent [25].

\section{Complications}

There were 2 complications in this study, one $(7.7 \%)$ in the single level group and one $(20 \%)$ in the double level group. In the single level group 1 patient had removal of prosthesis due to device failure and hypermobility. In the double level group, one patient had temporary dysphagia and dysphonia. In Lei Cheng et al. [20], there were no spontaneous fusions and no device failures in the artificial disc group. One patient has a deep vein thrombosis in the artificial disc group, and one patient has dysphagia in the control group.

In Goffin J et al. [25] the single-level study, there were three reinterventions at the treatment level. They included an evacuation of a prevertebral hematoma, a posterior foraminotomy without device involvement to treat residual symptoms. While In the bi-level study, one patient experienced CSF leak while decompressing posteriorly. In addition, there were four reinterventions at the treatment level that included an evacuation of an epidural hematoma, an evacuation of a prevertebral hematoma, a repair of a pharyngeal tear/ esophageal wound.

Radiologic outcome: The global range of movement increased by mean of 9.8 degrees in the single level group, on the other hand global range of movement increased my mean of 11.8 degrees in the double level group, while it is increased by mean of 9 degree in the hybrid group. These goes in accordance with other related studies; Seok Woo Kim et al. [21] reported that global range of movement increased by 3.5 degrees in the artificial disc group. Coric et al. [26] reported that it improved by 0.91 degrees in the combined arthroplasty group.

In Goffin et al. [25], At the 1-year follow-up, $88 \%$ of the patients in the single-level and $86 \%$ of the patients in the bi-level study exhibited motion equal to or greater than 2 degrees. At the 1-year follow-up, $93 \%$ of the patients in the single-level study exhibited motion equal to or greater than 2 degrees. CepoiuMartin M et al. [27], artificial cervical disc arthroplasty (ACDA) is a surgical procedure that may replace cervical fusion in selected patients suffering from cervical degenerative disc disease. Within 1 year of follow-up, the effectiveness of ACDA appears similar to that of cervical fusion. Weak evidence exists that ACDA may be superior to fusion for treating neck and arm pain.

Richards 0 et al. [28] documented that there is inadequate evidence to promote extensive use of artificial discs for cervical spondylosis, despite promising short-term and intermediate clinical outcomes. Despite the size of investment and research into arthroplasty outcomes, long-term follow-up has yet to be completed and has not convincingly demonstrated the effect of artificial discs on adjacent segment disease.

While Coric D et al. [26] stated that cervical total disc replacement allows for neural decompression and clinical results comparable to ACDF. Cervical disc replacement was associated with a significantly greater overall success rate than fusion while maintaining motion at the index level. Furthermore, there were significantly fewer disc replacement patients showing severe adjacent-level radiographic changes at the 1-year follow-up.

\section{References}

1. Phillips FM, Garfin SR (2005) Cervical disc replacement. Spine 30(17 Suppl): S27-33.

2. Bartels RH, Donk R, van der Wilt GJ, Grotenhuis JA, Venderink D (2006) Design of the PROCON trial: a prospective, randomized multi-center study comparing cervical anterior discectomy without fusion, with fusion or with arthroplasty. BMC Musculoskeletal Disord 7: 85.

3. Nabhan A, Ahlhelm F, Shariat K, Pitzen T, Steimer O, et al. (2007) The ProDisc-C Prosthesis: Clinical and Radiological Experience 1 Year after Surgery; Spine (Phila Pa 1976) 32(18):1935-1941.

4. Sasso RC, Smucker JD, Hacker RJ, Heller JG (2007) Artificial Disc Versus Fusion: A Prospective, Randomized Study With 2-Year Follow-up on 99 Patients. Spine 32(26): 2933-2940.

5. Kawashima M, Tanriover N, Rhoton AL, Matsushima T (2003) The transverse process, intertransverse space, and vertebral artery in anterior approaches to the lower cervical spine. J Neurosurgery (Spine) 98(2): 188-194.

6. McAfee PC (2004) The indications for lumbar and cervical disc replacement. Spine J 4(6 Suppl): 177S-181S.

7. Albert TJ, Eichenbaum MD (2004) Goals of cervical disc replacement. Spine J 4(6 Suppl): 292S-293S.

8. Pracyk JB, Traynelis VC (2005) Treatment of the Painful Motion Segment: Cervical Arthroplasty. Spine (Phila Pa 1976) 30(16S): S23-S32. 


\section{Open Access Journal of Neurology \& Neurosurgery}

9. Porchet F, Metcalf NH (2004) Clinical outcomes with the Prestige II cervical disc: preliminary results from a prospective randomized clinical trial. Neurosurg Focus 17(3): E6.

10. Kienapfel H, Koller M, Hinder D, Georg C, Pfeiffer M, et al. (2004) Integrated Outcome Assessment After Anterior Cervical Discectomy and Fusion: Myelocompression But Not Adjacent Instability Affect Patient-Reported Quality of Life and Cervical Spine Symptoms. Spine 29(22): 2501-2509.

11. Baba H, Furusawa N, Imura S, Kawahara N, Tsuchiya H, et al. (1993) Late radiographic findings after anterior cervical fusion for spondylotic myeloradiculopathy. Spine 18(15): 2167-73.

12. Wigfield C, Gill S, Nelson R, Langdon I, Metcalf N, et al. (2002) Influence of an artificial cervical joint compared with fusion on adjacent leve motion in the treatment of degenerative cervical disc disease. J Neurosurg 96(1 Suppl):17-21.

13. Eck JC, Humphreys SC, Lim TH, Jeong ST, Kim JG, et al. (2002) Biomechanical Study on the Effect of Cervical Spine Fusion on Adjacent-Level Intradiscal Pressure and Segmental Motion. Spine (Phila Pa 1976) 27(22): 2431-2434.

14. DiAngelo DJ, Roberston JT, Metcalf NH, McVay BJ, Davis RC (2003) Biomechanical Testing of an Artificial Cervical Joint and an Anterior Cervical Plate. J Spinal Disord Tech 16(4): 314-323.

15. Schwab JS, DiAngelo DJ, Foley KT (2006) Motion Compensation Associated with Single-Level Cervical Fusion: Where Does the Lost Motion Go? Spine 31(21): 2439-2448.

16. Hwang SL, Hwang YF, Lieu AS, Lin CL, Kuo TH, et al. (2005) Outcome Analyses of Interbody Titanium Cage Fusion Used in the Anterior Discectomy for Cervical Degenerative Disc Disease. J Spinal Disord Tech 18(4): 326-331.

17. Ragab AA, Escarcega AJ, Zdeblick TA (2006) A Quantitative Analysis of Strain at Adjacent Segments After Segmental Immobilization of the Cervical Spine. J Spinal Disorder Tech 19(6): 407-410.

18. Chang UK, Kim DH, Lee MC, Willenberg R, Kim SH, et al. (2007) Range of motion change after cervical arthroplasty with ProDisc-C and prestige artificial discs compared with anterior cervical discectomy and fusion. Journal of Neurosurgery Spine; 7(1):40-6, Jul 2007.

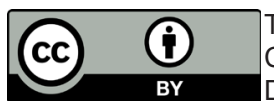

This work is licensed under Creative Commons Attribution 4.0 Licens DOI: 10.19080/OAJNN.2018.08.555748
19. Dmitriev AE, Cunningham BW, Hu N, Sell G, Vigna F, et al. (2005) Adjacent Level Intradiscal Pressure and Segmental Kinematics Following A Cervical Total Disc Arthroplasty: An In-Vitro Human Cadaveric Model. J Neurosurg Spine 30(10): 1165-1172.

20. Cheng L, Nie L, Zhang L, Hou Y (2009) Fusion versus Bryan Cervical Disc in two-level cervical disc disease: a prospective, randomized study. Int Orthop 33(5): 1347-1351.

21. Kim SW, Limson MA, Kim SB, Arbatin JJ, Chang KY, et al. (2009) Comparison of radiographic changes after ACDF versus Bryan disc arthroplasty in single and bi-level cases. Euro Spine J 18(2): 218-231.

22. Ryu SI, Mitchelle M, Kim DH (2006) A prospective randomized study comparing a cervical carbon fiber cage to the Smith-Robinson technique with allograft and plating up to 24 months follow up. Eur Spine J (15): 157-164

23. Vavruch L, Hedlund R, Javid D, Lesziewski W, Shalabi A (2002) A prospective randomized comparison between the cloward procedure and a carbon fiber cage in the cervical Spine: a clinical and radiologic study. Spine 27(16):1694-16701.

24. Lafuente J, Casey ATH, Petzold A, Brew S (2005) The Bryan cervical disc prosthesis as an alternative to arthrodesis in the treatment of cervical spondylosis. J Bone Joint Surg Br 87(4): 508-512.

25. Goffin J, Geusens E, Vantomme N, Quintens E, Waerzeggers Y, et al. (2004) Loon J Long-term follow-up after interbody fusion of the cervical spine. J Spinal Disord Tech 17(2):79-85.

26. Coric D, Cassis J, Carew JD, Boltes MO (2010) Prospective study of cervical arthroplasty in 98 patients involved in 1 of 3 separate investigational device exemption studies from a single investigational site with a minimum 2-year follow-up. J Neurosurgery Spine 13(6): 715-721.

27. Cepoiu-Martin M, Faris P, Lorenzetti D, Prefontaine E, Noseworthy T, et al. (2011) Artificial cervical disc arthroplasty: a systematic review. Spine (Phila Pa 1976) 36(25): E1623-E1633.

28. Richards O, Choi D, Timothy J (2012) Cervical arthroplasty: the beginning, the middle, the end? Br J Neurosurgery 26(1): 2-6.

Your next submission with Juniper Publishers will reach you the below assets

- Quality Editorial service

- Swift Peer Review

- Reprints availability

- E-prints Service

- Manuscript Podcast for convenient understanding

- Global attainment for your research

- Manuscript accessibility in different formats

( Pdf, E-pub, Full Text, Audio)

- Unceasing customer service

Track the below URL for one-step submission

https://juniperpublishers.com/online-submission.php 